\title{
JOHN DEWEY'S RECONSTRUCTION OF THE REFLEX-ARC CONCEPT AND ITS RELEVANCE FOR BOWLBY'S ATTACHMENT THEORY
}

\author{
Gert J. J. Biesta', Siebren Miedema \\ and Marinus H. van IJzendoorn
}

\begin{abstract}
SUMMARY: In "The Reflex Arc Concept in Psychology" (1986), John Dewey gives a reconstruction of the reflex arc concept which forms the starting point of a 'transactional paradigm' which is fundamental for all aspects of Dewey's work. In this article we start with a reconstruction of Dewey's paradigm. Next we show that Bowlby's attachment theory fits very well within such a transactional paradigm because it is based on ethology. A closer analysis, however, shows that the place of the mental in attachment theory is not completely consistent with the evolutionary assumptions of the transactional paradigm, and it is suggested that this problem can be solved from a Deweyan perspective.
\end{abstract}

\section{Introduction}

In 1896 John Dewey's “The Reflex Arc Concept in Psychology" was published (Psychological Review, 3, July 1896, 357-370; EW5:96-1092). This article has not only been considered a crucial step in the development of Dewey's thinking (cf. Bernstein, 1966, p. 15; Hahn, 1969, p. 27; Smith, 1973, p. 122; Slecper, 1986, p. 21; Alexander, 1987, p. 41), but also an important step in the development of psychology (cf. Langfeld, 1943; Murphy, 1961, p. 27, 29; McKenzie, 1975, p. xiv-xv). In this article Dewey criticizes the way the physiological idea of the reflex arc is used in psychology. The alternative view of behavior and the explanation for behavior that Dewey develops, is almost unanimously considered to be the starting point for functionalism in psychology (cf. Titchener, 1898, p. 451; Langfeld, 1943, p. 148; Flugel, 1964, p. 194; Bernstein, 1966, p. 15; Phillips, 1971, p. 566; Eisenga, 1973, p. 102; Verbeek, 1977, p. 141; Leahey, 1987, p. 270-271).

We shall draw on this article to introduce Dewey's position and give an cvaluation of its topicality. We shall then confront Dewey's ideas with some aspects of John Bowlby's attachment theory. It should become apparent that Dewcy has formulated the paradigm within which attachment theory can be placed. Looking at attachment theory from a Deweyan perspective enables

1 Research for this article by the first author is supported by a grant from the Netherlands Organization of Scientific Research (N.W.O.).

2

The complete works of John Dewey are published by Southern Illinois University Press, and are diivided into The Early Works (1882-1898), The Middle Works (1899-1924), and The Later Whate t10se 1052) Thou are referred in as FW. MW or LW followed by a page number. 
one to indicate which elements in the theoretical framework of attachment theory need further elaboration and how this might best be approached.

\section{The Reflex Arc Concept in Psychology and Dewey's Critique}

By the end of the nineteenth century psychologists were convinced that it was possible to overcome the dualistic presuppostions of associationist psychology. Physiology had provided the structural unit of afferent nerves, central nervous system and efferent nerves. Psychologists transposed this unit of structure into a unit of function of peripheral stimulus, central processing and motor response. This 'reflex arc' model was thought sufficient to explain human behavior (cf. Smith, 1973). The model resolved both the matter-form dualism ('sensation' and 'idea') of associationist psychology (by locating sensations and ideas in one process), and the body-mind dualism (by taking the mind to be the processes in the brain). Human behavior could now be explained from the physical, anatomical structure which meant that no essental distinction between anımal and human behavior was to be made. The model was, therefore, in agreement with the theory of evolution.

In his article Dewey expresses the opınion that by using the idea of the reflex arc concept in psychology "the principles of explanation and classification which the reflex are idea has replaced (...) are not sufficiently displaced" (EW5:96). According to Dewey " $(\mathrm{t})$ he older dualism between sensation and 1dea is repeated in the current dualism of peripheral and central structures and functions; the older dualism of body and soul finds a distinct echo in the current dualism between stimulus and response." (EW5:96). This is caused by the fact that the sensori-motor circuit or system is interpreted from "preconceived and preformulated ideas of rigid distinctions between sensations, thoughts and acts." (EW5:97). As a result psychological theory-building starts with "disjointed parts" and must then attempt to explain how the separate parts work together or interact. In Dewey's opinion attempts to explain the interaction either by introducing an "extra-experimental soul" or by giving an explanation in terms of "mechanical push and pull" (EW5:100), must be refuted because they contradict the biological-evolutionary points of departure which form the basic assumptions both of physiological psychology and of Dewey hımself. ${ }^{3}$

Because the theory of evolution "include(s) man under the same gencralization with other facts of nature" (EW1:210), an ontological dualism that presupposes two substances (mind and body) is impossible. This means

\footnotetext{
3 Although functionalism can better be vicwed as a line of reasoning than a red school of thought (see, c g, I cahcy, 1987, p 278, Verbech, 1977, p 126, Eisenga, 1973, p 101), one of the essential char acteristics of this line of reasoning is that it bases psychology on evolutionary principles (both Darwınınan and Lamarchlan) An claborate account of functionalısm can be found in Eisenga, 1973, especially Chapter 5
} 
that an "extra-experimental soul" does not fit into a physiologically based psychological theory.

Dewey also rejects the idea of "mechanical push and pull," because it presupposes an organism at rest that can only be activated by stimuli from the environment. This notion of an isolated, autonomous organism is also contradictory to the theory of evolution. "The idea of environment is a necessity to the idea of organisms, and with the conception of environment comes the impossibility of considering psychical life as an individual, isolated thing developing in a vacuum." (EW1:56). Organism and environment are not from the outset two autonomous entities. "Only by analysis and selective abstraction can we differentiate the actual occurrence into two factors, one called organism and the other, environment." (LW5:220). This implies that the organism cannot be considered as an organism-at-rest, having a completely rested, neutral and unpreoccupied status. "(T)he state of the organism is one of action which is continuous" (LW5:223). It is against this background that Dewey reconstructs the reflex arc concept.

\section{Co-ordination}

An adequate psychological use of the reflex arc idea should not start with disjointed parts, but has to begin with an organic unity. "What is wanted is that sensory stimulus, central connections and motor responses shall be viewed ... as divisions of labor, functioning factors, within the single concrete whole, now designated the reflex arc" (EW5:97). "The process all the way around is assumed to be the unit" Dewey writes (in a letter to Angell; see Coughlan, 1975, p. 139). According to Dewey "this reality may most conveniently be termed co-ordination." (EW5:97).

Dewey gives a reinterpretation of "the familiar child-candle instance" from James' Principles of Psychology to demonstrate how he is using the term co-ordination. "The ordinary interpretation would say the sensation of light is the stimulus to the grasping as a response, the burn resulting is a stimulus to withdrawing the hand as response and so on." (EW5:97). But, from a psychological point of view, this analysis is inadequate. "Upon analysis, we find that we begin not with a sensory stimulus, but with a sensori-motor co-ordination, the optical-ocular, and that in a certain sense it is the movement of body, head and eye muscles determining the quality of what is experienced. In other words, the real beginning is with the act of seeing; it is looking, and not a sensation of light." (EW5:97). On the basis of this analysis Dewey concludes that "both sensation and movement lie inside, not outside the act" (EW5:98). Dewey is also using the term co-ordination in a more encompassing sense. With the stimulus-response analysis the whole process of secing light - reaching for it - burning the hand - withdrawing the hand, can only be characterized as "the replacing of one sort of experience by another" (EW5:99). Only a fragmentary account of the state of affairs can be 
given. Dewey, however, is able to show the connection between these sequential acts using the concept of co-ordination (see also EW5:99).

\section{The Status of the Mental}

It may seem that the concept of co-ordination must be considered a mental capacity because of the way in which Dewey uses the term. Such an assumption would imply that the mental retains a central position in Dewey's philosophy. This is, however, not the case. Dewey wants to do two things. On the one hand he wants to formulate a monistic psychology, because in a psychology consistent with the principles of evolutionary theory there can be no place for an ontological dualism between mind and matter. On the other hand Dewey wants to incorporate the mental into his psychology. The only way to solve this is to show the continuity between (primary) physiological processes and (secondary) mental functions. Dewey provides two arguments which sustain this conclusion. Firstly, he shows that the principle of coordination can be applied both to the most fundamental physiological level and to the more complex mental level. Secondly, he shows how the development from the fundamental (i.e., physiological) processes of co-ordination to the more differentiated (i.e., mental) processes of co-ordination should be conceived.

Co-ordination is primarily a physiological process. Dewcy typifies the 'primary quality' of the organism as "movement as self sustaining through sclection and assimilation of environment" (EW5:304). Within the organism a "specialization of labor" takes place with a "consequent need of interrelating or co-ordinating structure". That co-ordinating structure is the nervous system. "(T)he nervous system has one primary inclusive function: co-ordination of specialized activities to a common end." (EW5:308). In the process of cvolutionary development Dewey distinguishes between an "increasing range of co-ordination," "co-ordination of movements with each other" and "coordination of movements with sensory activities." Within this latter modus of co-ordination, Dewey distinguishes between "(a) reflex action, (b) instinct, (c) formed habit, (d) deliberative activity" (EW5:307) ${ }^{4}$. Where Dewey uses the term "deliberative," mental capacities (i.e., thinking) are first introduced. Thought plays no role at the level of 'reflex action' and 'instinct' and this is also the case with 'formed habits'. "Thought arises in conflict of activities, through the need of striking a balance, that is, of discovering the course of action which will reconcile a number of conflicting minor activities"

${ }^{4}$ Dewey uses the principle of co-ordination also in an even more extensive sense. In his course on Educational Psychology (1896) he distinguishes stages in child development; each stage is characterized by its own 'co-ordinatory task' (EW5:310-311). At the level of adolescence Dewey speaks of "Ihe Co-ordination of Onc's Activity as a Whole with That of Others in Socicty" (I:W5:311). 
(EW5:314). So Dewey gives thought a function in situations in which the continuity of action is at risk, in those situations in which it is not clear "what kind of responses the organism shall make" (Dewey, 1938, p. 107).

\section{Dewey's Transactional Paradigm}

Dewey typifies human behavior as a biological-physiological process of co-ordination, a continuing attunement of organism and environment to each other as a result of which both the organism and the environment change in order to realise a situation of optimal adaptation. The word 'optimal' might suggest that Dewey holds that it is possible to state which adaptation is absolutely optimal. Dewey, however, keeps telling us that both organism and environment change. So there cannot be one state of the organism that will always guarantee an optimal 'fit'. The activities of the organism bring about changes in the environment which in turn can disturb the state of equilibrium reached. 'Optimal' must be seen as strictly situational. In attachment theory a similar idea can be found in Hinde, who suggests that there is a range of behavioral strategies for adapting to different niches (cf. Hinde, 1982b).

According to Dewcy, the process of co-ordination becomes increasingly complex and encompassing. Mental functions originate within this process and fulfil a function in the increasing refinement of the ever more complex and encompassing processes of co-ordination. Dewey does not place the mental alongside the physical (as had been the case in psychology before Dewey) but neither does he deny the mental (as would become the case in psychology after Dewey). Dewey's functionalism does not stop at just indicating the function of thinking in the process of (evolutionary) adaptation (a sort of functionalism that, e.g., can be found in Titchener, 1898). Dewey shows that thinking is one of the functions of the organism; a function that has developed in the ongoing process of 'interaction' just as, for example, can be said of the digestive system.

While psychology (and philosophy) before Dewey had drawn heavily on concepts such as 'mind' and 'consciousness', the introduction of evolutionary ideas leads to a shift of attention from 'mind' to the interaction of organism and environment. "The old center was mind ... The new center is indefinite interactions ..." is Dewey's summary of this 'Copernican Revolution' (cf. LW4:232).

As we have citcd above: "Only by analysis and selective abstraction can we differentiate the actual occurrence into two factors, one called the organism and the other, environment." (LW5:220). Because of the fact that the term 'interaction' implies two separate entitites, Dewcy, in his later works, prefers to use the term 'transaction' to denote the initial totality within which, from a certain perspective and for certain reasons, organism and environment can be distinguished (cf. Dewey \& Bentley, 1960, p. 122-124). 


\section{Bowlby's Attachment Theory: 'Behavior Systems' and 'Control Theory'}

Bowlby's attachment theory is an ethological theory (Bowlby, 1988, p. 1) based upon "analytical biology and control theory, which together have elucidated the basic principles that underlie adaptive, goal-directed behavior" (Bowlby, 1982, p. 37). Ethology departs from the principles of evolutionary theory. Bowlby praises ethology for not only studying the morphological and physiological characteristics of animals from the Darwinian framework of adaptation-for-survival, but also their 'behavioral equipment' (cf. Bowlby, 1982, p. 54-55).

One of the central concepts in Bowlby's theory is the ethological concept 'behavior system'. A behavior system is a system postulated to explain behavior by thinking of more complex behavior as a compilation of, and cooperation between, more simple behaviors. The concept "is used in an explanatory sense to refer to systems postulated as controlling behavior" (Hinde, 1982b, p. 62). With the help of this concept, explanations of behavior are given in which there are "lower-level systems controlling behavioral acts," "control systems postulated to explain interrelations between the several types of behavior" and "higher-order control systems" (Hinde, 1982b, p. 66). Bowlby elaborates on this (hierarchically ordered) classification of behavior and behavior systems by differentiating (in increasing order of complexity) "reflexes," "fixed action patterns" and behavior in which "a fixed action pattern is combined with a simple sequence that is dependent on fecdback from the environment" (Bowlby, 1982, p. 67). Bowlby notes that "just as there are many different types of behavioral systems so there are a number of different ways in which their activities can be co-ordinated" (Bowlby, 1982, p. 74). Various more or less 'elementary' behavioral acts are observed and are then placed in a coherent system. This systematization is based on the function that more elementary behavior performs in reaching a certain goal, and provides the means by which ethology tries to explain behavior.

While in the more elementary 'behavior systems', patterns of behavior are such that they go 'straight for the goal', in the case of more complex behaviors (and the corresponding more complex behavior systems) principles of 'control theory' are introduced. The main concepts of control theory are 'sctting', 'set-goal' and 'fecdback' (Bowlby, 1982, p. 43). In the case of, for example, a thermostat the set-goal is keeping the temperature at a certain level and the setting is the actual temperature that is wanted. While in the case of a thermostat the 'setting' has to be instituted by a human being, it is also possible to envisage a system which reccives its setting from another system. Bowlby gives the example of automatic anti-aircraft guns which receive their information from a radar-screcn (cf. Bowlby, 1982, p. 44). It is Bowlby's opinion that "this type of system is replicated in living organisms" (Bowlby, 1982, p. 44). Which behavior system must be activated in what way, 
depends on the comparison between the current situation and the situation that is wanted; a comparison in which 'feedback' plays an important part. Bretherton (1985) pointed out that the attachment behavior system must not be seen as a system-at-rest that is switched on to reach the set-goal and is switched off when the set-goal is reached. According to Bretherton the attachment behavior system is always active in coordinating different subsystems to reach and maintain the set-goal.

When control theory starts to play a role in the ethological explanation of behavior, cognitive capacities make their entry. It is evident that "ultimately 'goal-directed' bchaviour must imply that the animal has some model or correlate of the goal situation before that situation is achieved, and the behavior is governed by the discrepancy between current and goal situations. (...) An internal correlate of the goal can, but need not, imply cognitive abilities on the part of the animal" (Hinde, 1982a, p. 76). According to Hinde the hesitation of ethologists to introduce cognitive powers in explaining "complex social behaviour of higher mammals" is understandable but inappropriate. This hesitation has led, unfortunately, to "the neglect of many interesting phenomena" (Hinde, 1982a, p. 76-78).

Bowlby assumes that behavior systems are adapted to the environment in which they originated because they are the product of the evolutionary process of variation and selection. This means that nowadays behavior systems can only function adequately in a situation that does not differ too much from the original 'environment of evolutionary adaptation' (cf. Bowlby, 1982, p. 47; Bowlby does not make clear what he means exactly by 'too much'). This implies that the organism must be able to recognize certain characteristics of (or characteristic patterns in) the environment. So, according to Bowlby, we must presuppose that "the individual organism has a copy of that pattern in its CNS and is structured to react in special kinds of ways when it perceives a matching pattern in the environment and in other kinds of ways when it perceives no such pattern" (Bowlby, 1982, p. 48). "(A)s well as having equipment that enables them to recognise special parts of their environment, members of all but the most primitive phyla are possessed of equipment that enables them to organise such information as they have about the world into schemata or maps" (Bowlby, 1982, p. 48). Bowlby prefers to speak of a 'working model' instead of a 'cognitive map', because the latter is a too static concept (cf. Bowlby, 1982, p. 80). The individual can, as it were, look at, change and adjust the model and can use the model as a reference to plan his actions. The notion of "a model in the brain is that it constitutes a toy that is yet a tool, an imitation world, which we can manipulate in the way that will suit us best, and so find out how to manipulate the real world, which it is supposed to represent" (Bowlby, 1982, p. 80). By the use of language we can exchange our working models so that we need not re-invent the wheel over and over again. 
So in Bowlby's elaboration of attachment theory two cognitive abilities are postulated: “(a) a means of receiving and storing instructions regarding the set-goal, and (b) a means of comparing the effects of performance with instruction and changing performance of it" (Bowlby, 1982, p. 70).

\section{Discussion}

A comparison of Dewey's ideas with attachment theory shows that both depart from evolutionary theory. In both cases we also find a similar strategy for the explanation of behavior: complex behavior is explained by seeing it as a co-ordinated composition of more elementary behavior, and elementary bchavior is in the end viewed as biological-physiological. From this we can conclude that the 'paradigm' for explaining behavior Dewey formulated around the turn of the century has, in the last two or three decades, led to a flourishing research-program, especially since the introduction of ethology into psychology. 5

Dewey's significance lies in the fact that he has shown that an elaboration of (monistic) evolutionary principles need not imply that there is no place for mental 'faculties' in the explanation of human behavior. On the contrary: the mental must be considered as real as the material (the physiological). There is no argument for viewing certain 'results' of the process of evolutionary development (as, e.g., the mental, but also language and culture) as having a lower status or as being less relevant to the process of adaptation and change than other 'results' (as, e.g., reflexes or the digestive system).

When we apply Dewey's elaboration of the evolutionary principles to attachment theory, we are led to the conclusion that the latter is unclear on the issue of the status of the mental. Whilst attachment theory considers the physiological-biological level to be real, it is often the case that as soon as mental functions are introduced in explaining behavior, recourse is made to the level of explanation. Ethology wants to explain behavior by postulating behavior systems. Hinde describes an attachment behavior system as "a system postulated as controlling the several types of attachment behavior" (Hinde, 1982b, p. 64). To be able to explain more 'complex' behavior, the principles of control theory are applied. Exactly at the point at which those principles are introduced, mental capacities are presupposed in order to arrive at an adequatc explanation.

In attachment theory, then, there is a difference between the ways in which the physiological and the mental level are discussed. This difference can be partly traced to a difference between description and explanation. But

5 In theoretical psychology there is also a reassessment of Dewcy's idcas. Sce, for cxample, Natsoulas (1983) who discusses the way in which the concepts 'conscious' and 'consciousness' should be used and claborates explicilly on idcas Dewey formulated as early as 1906 (see Dewey, 1906). 
besides the fact that, from a philosophical point of view, the validity of such a rigid distinction between description and (theoretical) explanation can be questioned, Dewey has shown us that in this case there is no need to make any such distinction. Moreover, any such distinction is contrary to the evolutionary principles subscribed to by attachment theory.

We conclude that further research needs to be done into the ways in which the mental is used in attachment theory. We think that a Deweyan perspective might be helpful in realizing a more adequate conceptualization of the mental. A reconceptualization is not only necessary for theoretical reasons, that is, to get a theory that is consistent with its basic evolutionary assumptions. But also, to the extent to which attachment theory ascribes to mental capacities a direct influence on behavior, a more adequate and consistent way of viewing these capacities can contribute to the practical relevance of attachment theory.

\section{References}

Alexander, Th. M. (1987). John Dewey's Theory of Art, Experience and Nature: The Horizons of Feeling. Albany: State University of New York Press.

Bernstein, R. J. (1966). John Dewey. New York: Washington Square Press. Bowlby, J. (1982). Attachment and Loss. Volume I: Attachment, (2nd cd.). New York: Basic Books.

Bowlby, J. (1988). A Secure Base. Clinical Applications of Attachment Theory. London: Routledge.

Bretherton, I. (1985). Attachment Theory: Retrospect and Prospect. In I. Bretherton \& E. Waters (Eds.), Growing points of attachment theory and rescarch. Monographs of the Society for the Research of Child Development, 50, (1-2, Serial No. 209), 3-37.

Coughlan, N. (1973). Young John Dewey. An Essay in American Intellectual History. Chicago and London: The University of Chicago Press.

Dewcy, J. (1884). The New Psychology. EW1:48-60.

Dewcy, J. (1887). Ethics and Physical Science. EW1:205-226.

Dewey, J. (1896). The Reflex Arc Concept in Psychology. EW5:96-110.

Dewey, J. (1896). Educational Psychology: Syllabus of a Course of Twelve Lecturc-Studies. EW5:304-327.

Dewey, J. (1906). The Terms ‘Conscious' and 'Consciousness'. MW3:79-82.

Dewey, J. (1929). The Quest for Certainty. LW4.

Dewey, J. (1930). Conduct and Experience. LW5:218-235.

Dewey, J. (1938). Logic. The Theory of Inquiry. New York: Henry Holt.

Dewey, J. \& Bentley, A. F. (1960/1949). Knowing and the Known. Boston: Beacon Press. 
Eisenga, L. K. A. (1973). Structuralisme, functionalisme en behaviorisme. De gedachte van een behavioristische revolutie in de psychologie. (Structuralism, functionalism, and behaviorism. The idea of a behavioristic revolution in psychology). Amsterdam: Vrije Universiteit (diss.).

Flugel, J. C. (1964). A Hundred Years of Psychology, 1833-1933. New York: Basic Books.

Hahn, L. E. (1969). Introduction. From Intuitionalism to Absolutism. In J. A. Boydston (Ed.), John Dewey. The Early Works, 1882-1898. Volume 1: 1882-1888, (pp. vii-xxi). Carbondale \& Edwardsville: Southern Illinois University Press.

Hinde, R.A. (1982a). Ethology. Its nature and relations with other sciences. London: Fontana.

Hinde, R. A. (1982b). Attachment: Some Conceptual and Biological Issues. In C. M. Parkes \& J. Stevenson-Hinde (Eds.), The Place of Attachment in Human Behavior, (pp. 60-76). New York: Basic Books.

Langfeld, H. S. (1943). Jubilec of the Psychological Review: Fifty Volumes of the Psychological Review. Psychological Review, 50, 143-155.

Leahcy, Th. H. (1987). A History of Psychology. Main currents in psychological thought. (2nd ed.). Englewood Cliffs, NJ: Prentice-Hall.

McKenzic, W. R. (1975). Introduction. Toward Unity of Thought and Action. In J. A. Boydston (Ed.), John Dewey. The Early Works, 18821989. Volume 5: 1895-1898, (pp. ix-xvi). Carbondalc \& Edwardsville: Southern Illinois University Press.

Murphy, G. (1961). "Some Reflections on John Dewey's Psychology". In University of Colorado Studies. Series in Philosophy, No. 2, pp. 26-34. Boulder: University of Colorado Press.

Natsoulas, Th. (1983). Concepts of Consciousness. The Journal of Mind and Behaviour, 4(1), 13-59.

Phillips, D. C. (1971). James, Dewey, and the Reflex Arc. Journal of the History of Ideas, 32, 555-568.

Sleeper, R.W. (1986). The Necessity of Pragmatism. John Dewey's Conception of Philosophy. New Haven and London: Yale University Press.

Smith, A. K. (1973). Dewey's Transition Picce: The Reflex Arc Paper. Tulane Studies in Philosophy, XXII, 122-141.

Titchener, E. B. (1898). "The Postulates of a Structural Psychology. The Psychological Review, 5, 449-465.

Verbeck, Th. (1977). Inleiding tot de geschiedenis van de psychologie. (Introduction to the history of psychology.) Utrecht/Antwerpen: Het Spectrum. 